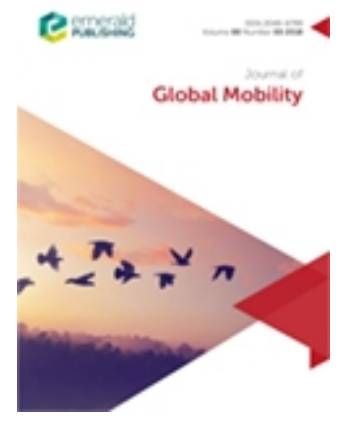

\title{
Radical changes in the lives of international professional women with children: from airports to home offices
}

\begin{tabular}{|r|l|}
\hline Journal: & Journal of Global Mobility \\
\hline Manuscript ID & JGM-03-2021-0029.R1 \\
\hline Manuscript Type: & Research Paper \\
\hline Keywords: & $\begin{array}{l}\text { home office, gender relations, mobile professional, international } \\
\text { professional women }\end{array}$ \\
\hline \multicolumn{2}{l}{} \\
\hline
\end{tabular}

\section{SCHOLARONE Manuscripts}




\title{
Radical changes in the lives of international professional women with children: from airports to home offices
}

\begin{abstract}
Purpose: This research was designed to discover the impact of restrictions connected with the COVID19 pandemic on the work and life of international professional women with children.

Design/methodology/approach: Qualitative, explorative research was conducted with twelve international professional women, who were professional women with children under 12; semistructured online interviews were used.

Findings: The radical decrease in international travel combined with an increase in online work and the increased demand of parenting resulted in work overflow, temporary re-traditionalisation of gender relations and a radical decrease in international mobility with respect to future prospects.

Originality: The exceptional case of the COVID-19 pandemic generated the need to understand the new situation, especially in the life of mobile professionals and women with small children.

Research limitation: This relatively small and non-representative sample needs to be complemented with further investigation into the social and economic consequences of restrictions connected with the COVID-19 pandemic.

Social implication: A large-scale crisis like the pandemic-related lockdown has had a tremendous effect on societies, including with regard to gender relations. Reflection will be needed in the aftermath of the crises and the gender equality achieved before the lockdown needs to be rebuilt.
\end{abstract}

Keywords: international professional women, home office, gender relations, mobile professional

\section{Introduction}

Not since World War II have there been such substantial changes in social relations, work and the economy of the world as those resulting from COVID-19. Moore and Collins (2021) declared that the consequences of the 2020 health crisis were worse than the 2008 global financial crisis. We cannot 
enumerate all of the aspects of social and economic life that have been affected since Spring 2020, but we can identify two facets of life have been hit hard, namely international mobility and gender relations. In this paper, the interplay of these social and economic phenomena is investigated by examining how the life of international professional women has changed. Since a severe reduction in international travel occurred as part of the restrictions, work and family life were significantly affected (Celigiuri et al., 2020; Moore and Collins, 2020). Curfews caused the closure of schools, kindergartens and day care centres, which resulted in home schooling and, in general, a lack of institutional support for childcare. Parents had to look after their children while also completing their work (Cluver et al., 2020; Verger et al., 2021). Each of these two changes had far reaching consequences for the group investigated, while the combination of the two proved even more distressing.

Research has shown that small numbers of women are internationally mobile. Although the number has grown in the past few decades, it remains under 20\% (Hutchings et al., 2012, Hutchings and Michailova, 2014 Salamin and Hanappi, 2014), and traditional international assignments with family relocations are extremely rare for professional women. Women with international careers tend to pursue alternative forms of international work, such as flexpatriation or frequent flyer international assignments, especially when they have small children (Salamin and Hanappi, 2014). While these forms of international work are more compatible with family life, they still have a significant impact on women's work-family balance (Greenhause and Beutell, 1985) and require extensive efforts and excellent organisation so that international work can be successfully completed. This is not independent of the fact that women, even when they live in a gender equal relationship, are often considered as the main care giver, and this traditional female role is strongly associated with being at home (Eagly and Wood, 1999). This is a result of the Industrial Revolution, during which public and private spheres were separated (Fraser, 2016). Recently, a new trend has changed work and life interaction: digitalization has moved men and women towards more integration of their work and family spheres instead of separating them (Primecz et al., 2016b), although this trend has affected men and women differently.

Investigation of the impacts of the COVID-19 pandemic-related restrictions on the work and life of international professional women might provide multiple insights. In this article, the impacts of 
lockdown on international professional women's life and work is first revealed, then gender relations are investigated in the shadow of the lack of travel, increased online work and home schooling, not to mention the lack of institutional support. Finally, future prospects are discussed with these women. To address these issues, qualitative, explorative research was conducted with twelve international professional women, each of whom had at least one child under 12. The working lives of these women were first affected by the cancellation of their international travel. Instead, a large part of their work was transformed into online meetings. This was complicated by the demands of childcare and home schooling. In the pre-lockdown period, most of them had well-functioning work and life arrangements which guaranteed some sort of gender equality with their partners, and they received well-organized support from different sources to help them accomplish their professional duties. During the lockdown, everything changed. Although they made efforts to maintain their professional results as much as possible, and most of them relinquished some parts of their jobs, they had to renegotiate their equality in their families with more or less success, and they developed a new equilibrium which became more difficult to maintain than it was before. Concerning the future, all the respondents predicted a radical decrease in international mobility in their professional lives, which they greeted with relief; this was unexpected, as they were all devoted to international work and had invested serious effort in developing their pre-lockdown lives and maintaining an international presence.

\section{Theoretical considerations}

\section{International professional women}

Caligiuri and Bonache (2016) defined global mobility as individuals (and often their families) being relocated from one country to another by an employer. Expatriation covers a similar concept and includes company-assigned expatriations and self-initiated expatriations under the umbrella of global mobility. Beyond these types of traditional expatriations, Shaffer et al. (2012) listed non-traditional ones, such as short-term assignments (Tahvanainen, et al. 2005), flexpatriation (Mayerhofer, et al. 2004), and international business travel (D. Welch, et al. 2007). Flexpatriates constitute a specific segment of the workforce in their own right (Demel and Mayrhofer, 2010). These are frequent flyers 
involved in various tasks, such as market exploration and technology transfer, who often travel upon short notice and who maintain their family and personal lives in their home country (Mayerhofer et al., 2004). Women often opt for these kinds of international careers rather than traditional expatriations in which their families, including spouse or partner, are relocated. In this way, they can avoid the 'glass border', gain international experience and still keep their family lives in their original settings (Salamin and Hanapi, 2014). While this seems to be an obvious choice which overcomes the gender bias of expatriate selection, it is still highly demanding for women, especially when they have small children, because society in general and individuals in particular consider women to be the main care givers (Eagly and Wood, 1999). Consequently, men, single women and older women tend to choose frequent flyer positions in contrast to women with small children, even though there are capable and talented candidates among all demographic groups. Women and men are equally interested and motivated to pursue international careers but the lives of women, especially those with small children, are affected by work/family issues (Fischlmayr, 2002; Fischlmayr and Kollinger, 2010; Hutchings and Michailova, 2014; Nagy and Primecz, 2014).

\section{Work-family balance - gender equality}

This reluctance to take international assignments is due to the fact that although equality in workplaces is nearly fully achieved, gender inequality within households persists (Catalyst, 2021). Women tend to work closer to their homes. This is especially true for women with small children, and it has serious consequences on a woman's career. Women display a deeper commitment to work while they remain responsible for the children and the household, meaning that they handle a double burden (Wheatley, 2013). Work-family balance is a persistently unsolvable issue for most women due to gender roles (Eagly and Wood, 1999), and two strategies basically exist: (1) set clear boundaries between work and family and maintain them as two separate fields or (2) integrate the two spheres and handle both in a synchronised manner. Women rarely have a choice to separate their roles, especially when working at home or in close proximity to home. They are often the primary caregiver and solve problems connected with children who are ill or when school issues occur. Men, on the contrary, might maintain separate work and family spheres, often when they work from home, and tend to have a separate room in which 
to work, while their wives shield them from the children, distractions and unwanted visitors and telephone calls. Women commonly work in a communal area (such as the kitchen or living room) and have to look after children at the same time (Sullivan and Lewis, 2001). Gender equality rarely derives from separate roles (McKarty and Moon, 2018) and this gendered practice sustains inequality and eventually leads to many women being overworked on a daily basis.

Greenhouse and Beutell (1985) highlighted several sources of work-family conflict, such as inter-role conflict deriving from the opposing pressures of an individual's different roles, which can be manifested in time-based conflict, strain-based conflict and behaviour-based conflict. Fischlmayr and Kollinger (2010) pointed out that the attention in early studies focussed on causes and consequences of work/family conflicts was shifting towards how family and work interfere with each other and how these interferences can be handled individually and by organisational support. While early work/family researchers kept the assumption of rigid gender roles as a given (Eagly and Wood, 1999), Grünberg and Matei (2020) went further by problematising work/family conflict as an objective and homogenous phenomenon that is equally relevant across cultures and categories of people. They argued that (1) work/family conflict/balance do not exist externally to the person; (2) it emerges from lived experience and is shaped by societal pressures; and (3) consequently, work/family conflict is a mode of understanding of the lived realities of the individuals involved. Grünberg and Matei (2020) did not argue that women can fully liberate themselves from societal pressures including those imposed by gender roles, but women also have agency, especially in their immediate family and work to develop a work/family interaction which is relatively comfortable for them. This means women can negotiate a less traditional division of labour related to household duties and child care with their partners and immediate families and, consequently, women with even small children become capable of pursuing similar careers as men, including international work. The most important condition of this unusual gender role is family support.

\section{Radical change in work setting due to COVID-19 restrictions}

In this highly globalised situation within the given gender regime, a highly contagious disease appeared, and most countries introduced a curfew and lockdown with international travel restricted to a minimum 
(Caligiuri et al., 2020; Moore and Collins, 2021; Nagarajan and Sharma, 2021). Consequently, many people began to work from their homes using online platforms, and unnecessary travel and social contacts were reduced and international travel all but disappeared (Jackson, 2020). International commuters were stuck in their homes and international conferences were replaced by online events. This affected all aspects of life, including gender relations. This change of social setting can be defined as a force majeure, and in the situation, most people reacted by trying to reduce the complexity of disturbance and to return to the well-known traditional solutions. The first reports on the social consequences of COVID-19 related restrictions forcing many professional women and men to work from home, mixed with the presence of their children and home schooling, indicated that women tended to serve their children's needs and partly their partner's while subjugating their own interests and wellbeing, thus sacrificing their professions for their family members' needs. A clear dissatisfaction among women was expressed in forms of reflection (Hennekam and Shymko, 2020).

Based on a survey with a large sample, Fodor et al. (2020) pointed out that women with school-aged children spent nine more hours providing childcare than they had before the lockdown, resulting in 11.5 working hours each day, which was five hours more than fathers on average spent with their children. Men who did not have paid work increased their childcare hours much more than their counterparts with paid work. While the existence of paid work for men had an impact on the number of hours spent at home with children, women increased their number of hours spent with children independently of their employment status. Men and women working in home offices increased the number of hours spent providing child care, and women with or without paid work in a home office spent most of their time with their children's education and care. This gender gap remained consistent for all social groups throughout the sample, with an average of five more hours devoted by mothers to their children. Geambasu et al. (2020) completed qualitative research on similar issues and concluded that retraditionalisation of gender roles manifested in the number of hours of child care and education and a focus on traditional parenting roles which happened immediately after the beginning of the lockdown with home schooling and massive home office work. In addition, mothers tended to support their 


\section{Methodology}

An explorative study with a subjective epistemology was used due to the unstructured nature of the research inquiry and the relatively limited previous information about the issue. An interpretive research paradigm was chosen in line with the tradition of cross-cultural management (Chevrier, 2009, 2011; Primecz et al., 2009; Romani et al., 2011), as initiated by Geertz (1973). Three pillars of the interpretive paradigm were consciously maintained throughout the study: relying on the actors' perspectives, letting meanings emerge from the interviewees, and allowing the saturation of empirical material to determine the duration of data collection. The qualitative research included open-ended questions, and the narrative nature of the interviews facilitated the actors' to reveal their perspectives. In line with interpretive paradigms, there was no attempt to discover laws but rather to understand the specific situations and experiences of the interviewees (Welch, C. et al., 2011; Primecz et al., 2016a; Romani et al., 2018; Primecz, 2020). The focus of our study was on the uniqueness of the cases considered and particularisation - instead of generalisation. Instead of causal explanations, an interpretive tradition was pursued that put emphasis on 'Verstehen' instead of 'Erklären' (Schwandt, 2000; Welch et al., 2009). 
The relative scarcity of women with extensive international travel limited the choice of method to develop the sample. The purposive sample was built on convenient contacts searched in the author's personal network: international professional women who travelled abroad frequently (a minimum of six times a year) for work and professional purposes prior to the global lockdown and who have a child(en) under age 12. Only two women in the author's immediate network positively responded and fit the criteria. Additional women were contacted through recruitment from international colleagues and their networks, meaning that most interviewees were unknown to the researcher before the online interviews. While the aim was for maximum variation in country of origin, all interviewees were European: four women from Hungary, two from Romania, two from Finland and one each from Austria, France, Spain and the United Kingdom, resulting in a non-representative distribution of country of origin. Consequently, it is not possible to derive precise and representative statements from this sample but only preliminary ideas about issues which emerged in this situation. A larger possible representative or at least more proportional sample should be used to reach a more reliable conclusion. The majority of interviewees had international experience (details in Table 1), having lived, studied or worked abroad. Interviews were conducted in the first wave of the pandemic and lockdown between April and June 2020. The average length of the interviews was 36 minutes and they were conducted through the online platforms of Skype and Microsoft Teams. All interviews were recorded and typed verbatim by professional typists. Five interviews were conducted in Hungarian, the mother tongue of the given interviewees and interviewer, and seven interviews were conducted in English, a working language of all of the remaining interviewees and the interviewer and the native language of one of the interviewees. While various distortions might affect the comprehension of interviews, including imperfections of online platforms and possible language barriers on both the interviewee and interviewer sides, the reality of lockdown made this limited communication possible, which was actually similar to the reality of work for both the interviewees and the interviewer at the time of the crisis. Table 1 provides some details about the interviewees.

Insert Table 1 about here 
Interview analysis was conducted with the help of NVivo 9 software. As a first step, open coding was undertaken to identify emergent themes, which are presented in Table 2. Interview questions covered career steps and international experience prior to the lockdown, work-life balance issues connected with children and the impact of lockdown on work and family. Questions were also asked about learning points, fears and future trajectories. Three main themes consequently emerged: (1) international professional womenwork-family arrangements of international professional women, (2) changes in work settings - unnecessary travel, (3) maintaining a good balance between professional work and family in a home office. After analysing the interviews, these two underlying issues could be identified: (1) a fight for gender equality in the pre-lockdown era and (2) efforts to maintain some sort of gender equality while working from home. Finally, most interviewees expressed their uncertainty about their futures. All of them claimed that the frequency of international travel would be reduced and most of them also stated that they were personally happy with this. Table 2 summarises the findings with the first order codes.

\section{Insert Table 2 about here}

\section{Empirical findings}

The women interviewed were - almost without exception - fascinated by international work. They liked travelling, encountering new cultures and working on multicultural teams, and they appreciated the creativity they derived from these experiences. Most of them had lived for a shorter or longer period abroad, one of them had dual citizenship as she had parents from different countries, and some of them had husbands or partners from other countries. Many educated women start their careers similarly to men, but when they give birth to their children, most of them hold back on their careers in order to combine family responsibilities and work; frequently, international travel is the part of their work which is radically reduced or even eliminated. The sample group of international experts in this research study were not typical women in this sense. They all maintained their international work. Some of them slightly reduced their international travel while they had infants, but most of them maintained their 
workload after a brief maternity leave, and some of them even increased their international duties after giving birth as they were invited to new (higher) positions at exactly that time. They were all very devoted to their jobs and found creative solutions regarding how to combine work with family obligations. Consequently, their family lives were characterised with better gender equality than many other families in their respective societies.

\section{International professional women work-family arrangements}

The interviewees travelled at least six times a year, although some of them had two or three international trips per month, meaning that they went abroad for 2-3 days almost every week or every second week. Several women reported that they attended at international meetings and conferences accompanied by their babies and their husbands, partners or a grandmother who took care of the babies while they attended the meeting or conference and that they fed their babies during breaks. Most women told these kinds of stories with a positive tone, but all reported that it was exhausting for everyone: the infant, the accompanying person and the woman herself. Thus, the interviewees considered this a temporary solution, and when they could disentangle themselves from travelling with babies, they preferred that their children stayed at home while they were on international assignments.

I was bringing the whole family, so it was always a bit tiring, but it was also nice because I was breast feeding, so I could have my family around, so I was bringing my family everywhere so my son have been a bit travelling with us, and then when I got my second child. (Annabelle)

So she [my daughter] was a little older, more than one and a half years old. I tried to arrange it that way that I should come home as quick as possible. So I just went and returned [after the meeting]. It was difficult at the beginning, but we learned to handle the situation. (Katalin)

Women had to rely on family members, most often the fathers of their children, and quite often grandmothers and sometimes babysitters. There was only one woman in the sample who had a regular babysitter since she had twins, and her babysitter worked for her from the time of the children's birth. At the same time, she relied on the father of their children when she travelled, as the babysitter worked only during the daytime; thus, the father was responsible for childcare in the evenings and at night when she was travelling. Another woman had a babysitter who had just left the family at the time of the interview because she had new career prospects as a freelance graphic designer. 


\section{Change in work setting - unnecessary travel}

Lockdown has had a huge impact on the work of the interviewees. Most of them worked in professions in which it was possible to work from home. At the beginning of the lockdown, it seemed that some time was released as many international meetings and conferences were cancelled and some went online. But it very quickly turned out that the amount of work somehow increased. A newly appointed project leader found herself without support in her home, and her team working in their home offices could not effectively support her work.

Professionally, the first six to eight weeks has been extremely difficult because before I had my team around and it was extremely easy, I mean, you know, to communicate [...] I end up suddenly having so many calls, like up to seven eight calls a day starting 8 finishing at 8 because we are all busy, having to take care of the kids at the same time, yeah it has been for us it's extremely exhausting. (Annabelle)

It was not only this woman with her leadership role who found it difficult and tiring; all interviewees reported that within a very short time, online meetings were overwhelming, and eventually, the individual work which was also part of most interviewees' tasks could not be completed.

I could focus on doing my work which even so I did not have to travel or even I did not have to go to my office, the amount increased because suddenly there was a lot of meeting, there was online meetings everybody thought everybody could attend everywhere because you are at home and there is no beginning and no end because we are available all the time, and at that time, I have to write a report for the [...] project. (Annabelle)

Most of the interviewees reported that the skills they had developed to effectively organise work were not successful in the new work arrangement, and the demands related to the work from employers or 
international partners increased. Most of them made compromises and omitted some tasks which seemed to be of a lower priority.

I got very tired. I think I worked twice or three times more than before. I had no time left. I literally escaped to jog three times a week for 45 mins because I didn't want anyone to speak to me. It was extremely tiring, and I had the continuous feeling that I could not proceed as I wanted, I have growing backlog and I never catch up. I could not work enough not to leave some unfinished work. And you know, I am not so young to be hyper-productive at midnight. (Katalin)

I haven't been of productive and, but as I said I think I realised that very, very early on, and I realised that actually if I, if I pushed myself to be as productive as before, I was supposed to have horrible time in lockdown because I know that then I would have to make serious changes, and but actually, I wasn't able to do that. (Charlotte)

Productivity was a major concern for all interviewees, and, at the same time, they reported with relief that much of their international travel had proven unnecessary. Most meetings could be successfully arranged without face-to-face interaction. Many of them explained that they already had a good professional relationship with their international partners, and this made the online discussion of essential issues possible. Some of them added that they were invited to meetings to which they could not previously have gone; since all meetings were online, including further participants was not difficult. Finally, it was also mentioned that although the professional work of international conferences could be completed online, and the networking part were considered as important for future work, it could not be fully replaced.

\section{Maintaining a good balance between professional work and family with a home office}

While the lockdown's impact on work was significant, its impact on family life was huge. The biggest challenge for all the interviewees was their work-family balance. While all of them had a welldeveloped routine for their normal work arrangements, the new situation provoked other solutions; parallel to the sudden increase in work, there was a sudden increase in parenting, as schools and kindergartens were closed, small children needed constant supervision and school-age children needed support for their education. Previous support from the family, for example, grandmothers and 
babysitters, also ended during the lockdown. Women alone or only with their husbands or partners had to handle the situation.

No support, we were completely alone with the kids, so no time with my partner, no time, we were for weeks, we were like flatmates, you know, giving each other the kids, I mean the evening I have been so tired and still I was working till two of the morning or three. And he was starting at five to be able take care of the kids so we didn't really have time together and I'm, we are really lucky to be a very solid couple, but I can imagine that for lot of couples this was extremely hard. (Annabelle)

Home schooling added an extra layer of difficulty. Even when children were quite independent, they needed parental attention for certain tasks, and it was surprising how important issues were taught during this period when no professional educator was available, for example, teaching how to divide in mathematics or how to write certain letters might not be easy to teach when someone has never learned pedagogy. Above all, all the women interviewed had principles about child rearing and education, and most of them did not want to compromise their children's healthy development because of the pandemic. Many of them mentioned that the use of gadgets, such as tablets, smartphones and laptops, had been strictly controlled, but when learning material for home schooling arrived through these tools, it was suddenly impossible to limit the use of such tools and the use of the Internet.

Most families developed a new schedule in which parents had their own time to complete their most important tasks and parenting was strictly divided. One family chose to work six days per week, and each parent had three full days to work and three full days for parenting and housework with time together on Sundays. This meant that instead of five work days, both parents worked three days per week. Another family decided that the father worked from 8 to 4 as he was almost constantly on calls, and the mother completed home schooling with their children, took care of their younger child, prepared food and completed housework; she then worked from $4 \mathrm{pm}$ until midnight and the father took care of their children and housework. For other families, it was the opposite - in one case, the professional woman had constant online meetings during office hours; another had to go out to work every day, as she was a medical doctor and worked with Covid patients. The fathers or partners in these families took care of their children and supported their children in home schooling when it was necessary. In these cases, the fathers were freelancers, and they worked when their wives took over care of the children. In one case, the father lost his job - he worked in the airline industry. Finally, some divorced or separated 
families could organise their lives by dividing parenting into weeks. When the children were not at home, the adults could work as much as possible, while in the weeks when children were at home, they essentially did not work.

None of the interviewees reported satisfaction with their work-family balance. They stated that it is only a temporary solution which they hope will be over soon. The imbalance reported by women was in most cases rather painful.

I decided then to put my expectation down and also to re-portion my work a bit, so for example, in the mornings I was really just dealing with emails or things that didn't really require much thinking because I was constantly having to talk about divisions to my son or, you know, quickly doing math performance or something with them. (Charlotte)

I sleep very [laugh] very few hours, I'm always overcome with situations but I think that this is my daughter deserves I, myself, deserve this time with her so this is the, my biggest point so I make all my efforts in terms of time of work and everything in order to have this time to be with her because of her because of me, of myself, because I think that it's for me it was a choice to be a mother. (Gloria)

The so-called home office was criticised for being an illusionary place where work/family could coalesce. One interviewee explained the impossibility of completing normal intellectual work when children are around.

I have been trying to explain for ages that this aspiration of home office [...] how it helps women, mothers, I think it is nonsense. [...] it is impossible to work quality intellectual work which needs deep thoughts. You might start to show infinite films to the children, but thank you, I do not want this. (Imola)

Another interviewee added that she needed uninterrupted time for deep thought and reflection, which is impossible when children need constant attention.

I'm struggling, mostly, and am really finding [...] I don't have time, I don't have an noninterrupted time, like quality time where you can, when you're not tired like a dog [laugh] and you can, you know, you're fresh and you can just have that moment of reflection of maybe just do the link in your head and thinking about things rather than acting. (Ramona)

Eventually, due to the growing pressure from work and the intention to avoid compromise in parenting, women had no other choice but to reduce or eliminate their own needs, such as individual activities, 
sports or entertainment, quality time with their partners, and even sleep. All of them switched to a mode of maximum productiveness in order to survive.

\section{Fight for gender equality in pre-lockdown era}

The underlying issue behind the situation dates back to the pre-COVID-19 era. These women consciously or unconsciously epitomised the feminist ideal of working women who made no compromises in their work when they became mothers. They successfully performed as professionals with international obligations and negotiated the family arrangements with their partners, which made it possible for them to be unencumbered workers, totally devoted to their duties and yet still be mothers. Many of them even had expectations of high quality parenting.

While, in theory, women are rarely discriminated against or put into inferior positions, in practice, women's professional attainment remains behind men's. This is often explained by motherhood: when women have small children, priorities change, and many women hold themselves back from professional life, either temporarily or permanently. The women in this research, however, did not follow the welltrodden path of this majority, and their lives before lockdown were characterised by a mild or strong fight for their equality. They either explicitly expressed their disagreement with women being in inferior professional positions, or they followed their professional call and practically organised their lives to support their professional ideals. All of them consciously or unconsciously followed the feminist ideal in which men and women are equal in professional and private life.

When I was at home, when we were both at home, we used to divide the care work that one of us is responsible for the mornings and the other is for the afternoon. This makes possible that one of us can start working early in the morning until kindergarten and school closes, and the other start working a bit later, but this parent can work until late. When one of us is abroad, then the parent who is at home has shorter workday. (Imola)

So my husband was, you know, from the beginning was helping with the children, so we were sharing this responsibility from the beginning, and he knew that this is important and, you know, or the very material part of my work to be travelling, so there for not a question that I would not be able to do it or I had to stop working. (Kirsi)

\section{Efforts to maintain some sort of gender equality with a home office}


Equality in professional and private life was hit by the crisis. Lockdowns cut off certain sources of support, for example, institutions (schools, kindergarten, day care), family support and other ad hoc help outside of families. In some countries, divorced parents could not organise their children's regular visits between households or sometimes even different cities (e.g., in Austria), while it was still possible in other countries (e.g., in Finland).

Those who lived together had to organise their daily routines to have time for their own work and provide the necessary care for their children. Previous arrangements collapsed because they had relied on further support. Beyond this, the workload increased in the majority of the cases. There was only one person who lost his job in these families, and while this actually provided a temporary solution for childcare, it obviously created the problem of not having the necessary income for the family. Moreover, in this case, the interviewee decided to separate from him, and this further complicated arrangements.

For the lockdown with the children and one of the main rules was every morning we would, they would work with one of the parents with them and then the other parent would be in the spare room working, and then in the afternoon, the kids have a free time and the parents would work so that was the plan, actually to be fair it worked very well, so I did most of the home teaching. (Charlotte)

A lot besides schooling and even though my husband took over most of the stuff, of course as long as you are available around as mum you always and yeah we did, our flat is not too big, so my husband installed a small desk in our sleeping room, so that I have because we don't have a separate working room. (Stella)

The interviews did not provide immediate insight into how hard these negotiations were for the families; it was only the women's narrative which was provided in this research. They all reported difficulties and they explained their situations as the best of all possible worlds given the circumstances. Nonetheless, survival was the order of the day and they definitely did not wish to live this life in the long term.

\section{Uncertainty about their future}

The women interviewed felt overwhelmed and were desperately awaiting the end of the pandemic and the lockdown. Their first concern was not to return to their work that involved international travel, which 
Many interviewees pointed out the costs of short-haul travel which proved to be recoverable with online meetings. Several interviewees also expressed their concern about the carbon footprint of intensive international travel, and highlighted that as we have learned how to avoid this short-haul travel, it is in our interest and the planet's not to return to these habits. Many of them added that they personally felt relieved that they would not have to travel as much as they used to.

I see a lot of advantages because travelling for work has been quite stressful for me to organise, always, to take care of the boy when I travel I need to arrange my travel times according to the working times of the father of my boy and so on, so yeah, it has made my life more easier definitely but for my work, I think it would be a little bit better for my work if I would be travelling, but it is not a big difference so I think after this lockdown travelling might decrease or it will not maybe get to the same level than before. (Norma)

The women interviewed also added that being with their loved ones was a good experience during lockdown, and small children were always unhappy when their mother was away.

I think we did we connect as a family a lot more than we probably would normally and because we were all together and I had never known the impact that travelling have on the kids, I mean they never liked me go away, and I understood that they are fine with it and they got used to it because I had always done it, but they never liked it, and so I think for them to have both home all the time was really lovely, [...] so my kids were very, very close. (Charlotte)

Finally, all the respondents expressed their concerns about the uncertainty of the future. They do not know how long they will have to be at home, what work arrangements there will be in the future, how schools and other institutions will operate in the future, what impact there will be on their children because of temporary social distancing from friends and family members (e.g., grandparents), how home 
schooling effects children's relationships with their parents, and the effects of missed professional education on children because important issues might have been overlooked during home schooling. There were also uncertainties connected with possible economic losses and work, and even risking of democratic values.

\section{Discussion}

The two distinct impacts of the restrictions connected to COVID-19 arrangements came from two separate directions: (1) the radical reduction of international travel and its replacement with online meetings directly affected the work of the women and (2) closure of institutional support for childcare and home schooling affected the women's private lives. Both had gendered consequences. The women's work horizons receded to the purely local from the international. The independence and freedom which was supported by the liberty of travel disappeared and it was replaced by the growing pressure of tasks derived from work and family. The work setting was far from ideal and interviewees received far less support for their work, and they also lost a large part of the support they had from families and beyond (e.g., grandparents, babysitters). There was no choice but to increase parenting. All these pressures moved women towards more traditional gender roles and parenting and household duties overruled the requirements of the workplace. The previously negotiated work/family balance could not be maintained in the new crisis situation.

Force Majeure, as Hennekam and Shymko (2020) showed, pushed men and women towards wellknown traditional gender roles (Eagly and Wood, 1999). They explained that 'individuals disclose their identity choices in demanding circumstances, they simultaneously search for justifications'. Women tended to care more, and men attempted their breadwinning role when they could, as has also been observed in other empirical research (Fodor et al., 2020; Geambasu et al., 2020). As one interviewee explained, 'I wanted to be a mother, I chose to be a mother' (Gloria), thereby giving a reason for prioritising her daughter in these difficult times after she returned from her highly demanding job of being a medical doctor during the daytime and fighting for the lives of COVID-19 patients. She still combined all her efforts to provide an education for her daughter that she believes is the best for her 
development. While her intentions are clear, these improvisations are bounded, since the choice of who to be in times of crisis remains constrained (Hennekam and Shymko, 2020). Home schooling was not their choice.

The literature has pointed out that the consequences of restrictions and isolation were many-fold. Women is this sample were devoted mothers who wanted to protect their children from the negative consequences of isolation as much as possible (Brooks et al., 2020; Cluver et al., 2020; Verger et al., 2021), were devoted international professionals who had chosen their career tracks and all of them had important international tasks to complete which were only possible online from a home office (Caligiuri et al, 2020) and only through self-exploitation. These women worked more than they had prior to the COVID-19 crises and they devoted more time and attention to parenting. Spending time with their loved ones other than their children and spending time on their personal wellbeing were radically reduced and work-life imbalance was pushed to an extreme: obligations were fulfilled by any means.

International professional women are not typical in the sense that their work prior to the border closures required intensive international travel and they had to negotiate work and life arrangements with their families to make it possible to participate in their work at the international level. Their lifestyles made it possible to pursue their careers with international obligations while having a relatively satisfactory work/family balance (Grünberg and Matei, 2020). The drastic changes in circumstances due to COVID19 made it impossible to again find a satisfactory balance, and they prioritised their children's wellbeing as far as they could by making compromises in their work. They also hoped that this demanding situation would not last long. The resulting re-traditionalisation of gender roles (Geambasu et al., 2020; Hennekam and Shymko, 2020) that occurred to different extents in these families was in sharp contrast with their pre-Covid-19 family arrangements.

Finally, when asked about their futures, the participants in this research were ready to give up their international careers. Not only did they realise that a number of tasks can easily be completed online without travel, their fatigue from travel and further exhaustion from their work and lifestyles, not to mention their environmental consciousness, made them hope that they would not travel as much in the future. They believed this will have consequences for everyone as international mobility will decrease. 
This is in line with predictions from the literature (Caligiuri, 2020; Nagarajan and Sharma, 2020), and it is a significant consideration for the theory and practice of global mobility.

\section{Conclusions}

The restrictions connected with the exceptional case of the COVID-19 pandemic have had a significant impact on international businesses, economies and society. Based on the qualitative investigation of the testimonies of twelve international professional women, the most important consequence of lockdown was the replacement of international mobility with online solutions, which most probably will result in a radical decrease in international travel compared with the pre-lockdown era. While the majority of the work could be completed in a home office, when it is about intellectual work, this impacted the genders differently. The loss of institutional support and decreased family support for childcare moved most women and men towards more traditional roles, and, consequently, the previous gender balance in families was challenged. In most cases, an almost satisfactory balance could be renegotiated within the family, while work-family imbalance was clearly present and work overload was typical.

The contribution of this research is manifold. For international businesses, the potential decrease in international mobility should be considered given the current possibilities of digitalisation which taught international players how to handle international work remotely, mainly supported by online digital platforms. For gender studies, exceptional circumstances provoked the re-traditionalisation of gender roles which might affect the number and proportion of expert women in international assignments. Finally, for women in international management, the consequences of the crisis must be investigated after the pandemic when women with parenting obligations can and will return to international work.

The limitation of this research is obviously the small sample of international professional women, which could be complemented by further research with similar samples or an extended sample of men and women in international business and expatriation; this could help us to understand the differences between genders with regard to how working parents were affected during this crisis. The sample itself was not representative, either by country of origin or by profession. This sample provides insights into 


\section{References}

Brooks, S. K., et al. (2020), "The psychological impact of quarantine and how to reduce it: Rapid review of the evidence", The Lancet, Vol. 395, pp. 912-920. https://doi.org/10.1016/ S01406736(20)30460-8

Caligiuri, P. and Bonache, J. (2016), "Evolving and enduring challenges in global mobility”, Journal of World Business, Vol. 51 No.1, pp. 127-141.

Caligiuri, P., De Cieri, H., Minbaeva, D., Verbeke, A. and Zimmermann, A. (2020), "International HRM insights for navigating the COVID-19 pandemic: Implications for future research and practice", Journal of International Business Studies, Vol. 51, pp. 697-713.

Catalyst (2021), "Women in the workforce - quick take, 2021, Feb. 11". Retrieved 07.06.2021 from: https://www.catalyst.org/research/women-in-the-workforce-global/

Chevrier, S. (2009), "Is national culture still relevant to management in a global context? The case of Switzerland”, International Journal of Cross-Cultural Management, Vol. 9, pp. 169-183.

Chevrier, S. (2011), "Exploring the cultural context of Franco-Vietnamese development projects: Using an interpretative approach to improve the cooperation process", Cross-Cultural Management in Practice: Culture and Negotiated Meanings, pp. 41-52.

Cluver, L., et al. (2020), "Parenting in a time of COVID-19", The Lancet, 395, e64. https:// doi.org/10.1016/S0140-6736(20)30736-4

Demel, B. and Mayrhofer, W. (2010), "Frequent business travelers across Europe: Career aspirations and implications", Thunderbird International Business Review, Vol. 52 No. 4, pp. 301-311.

Eagly, A.H. and Wood, W. (1999), "The origins of sex differences in human behavior. Evolved dispositions versus social roles", American Psychologist, Vol. 54 No. 6, pp. 408-423.

Fischlmayr, I.C. (2002), "Female self-perception as barrier to international careers?" The International Journal of Human Resource Management, Vol. 13 No. 5, pp. 773-783.

Fischlmayr, I.C. and Kollinger, I. (2010), "Work-life balance - a neglected issue among Austrian female expatriates", The International Journal of Human Resource Management, Vol. 21. No. 4, pp. 455-487.

Fodor, É., Gregor, A., Koltai, J. \& Kováts, E. (2021), "The impact of COVID-19 on the gender division of childcare work in Hungary", European Societies, Vol. 23 Sup. 1, pp. S95-S110, doi:10.1080/14616696.2020.1817522

Fraser, N. (2016), “Contradictions of Capital and Care”, New Left Review, Vol. 100, pp. 99-117.

Geambașu, R., Gergely, O., Nagy, B., Somogyi. , N.(2020), "Qualitative Research on Hungarian Mothers' Social Situation and Mental Health during the Time of Covid 19 Pandemic", Corvinus Journal of Sociology and Social Policy, Vol. 11 No.2, pp. 151-155. doi:10.14267/CJSSP.2020.2.11

Geertz, C. (1973), The Interpretation of Cultures, Basic Books, New York, NY. 
Greenhaus, J.H. and Beutell, N.J. (1985), "Sources of Conflict between Work and Family Roles", The Academy of Management Review, Vol. 10 No.1, pp. 76-88.

Grünberg, L and Matei, S. (2020). "Why the paradigm of work-family conflict is no longer

sustainable: Towards more empowering social imaginaries to understand women's identities", Gender, Work \& Organization. Vol. 27, pp. 289-309.

Hennekam, S. and Shymko, Y. (2020), "Coping with the COVID-19 crisis: Force majeure and gender performativity", Gender, Work, and Organization, Vol. 27, pp. 788-803. doi:10.1111/gwao.12479

Hutchings, K. and Michailova, S. (2014), "Women in international management: Reviewing past trends and identifying emerging and future issues", Hutchings, K. and Michailova, S. (Eds.), Research handbook on women in international management, Edward Elgar, Cheltenham, pp. 3-17.

Hutchings, K., Lirio, P. and Metcalfe, B. D. (2012), "Gender, globalisation and development: A reevaluation of the nature of women's global work", The International Journal of Human Resource Management, Vol. 23 No.9, pp. 1763-1787. doi:10.1080/09585192.2011.610336

McKarty, L. and Moon, J. (2018). "Disrupting the Gender Institution: Consciousness-Raising in the Cocoa Value Chain", Organization Studies, Vol. 39 No. 9, pp. 1153-1177. https://doi.org/10.1177/0170840618787358

Mayerhofer, H., Hartmann, L.C., and Herbert, A. (2004), “Career management issues for flex-patriate international staff”, Thunderbird International Business Review, Vol. 46, pp. 647-666.

Mayerhofer, H., Schmidt, A., Hartmann, L. and Bendl, R. (2011), "Recognising diversity in managing work life issues of flex-patriates", Equality, Diversity and Inclusion: An International Journal, Vol. 30 No. 7, pp. 589-609.

Moore, H.L. and Collins, H. (2021), "Rebuilding the post-Covid-19 economy through an industrial strategy that secures livelihoods", Social Sciences \& Humanities Open, Vol. 3 No. 1, pp. 100-113. https://doi.org/10.1016/j.ssaho.2021.100113

Nagarajan, V. and Sharma, P. (2021), "Firm internationalization and long-term impact of the Covid-19 pandemic", Managerial Decision Economy, pp. 1-15. doi:10.1002/mde.3321

Nagy B., Primecz, H. (2014), "Hard choices: Hungarian female managers abroad", Hutchings, K. and Michailova, S. (Eds.), Research Handbook on Women in International Management, Edward Elgar, Cheltenham, pp. 246-275.

Primecz, H. (2020), "Positivist, constructivist and critical approaches to international human resource management and some future directions", German Journal of Human Resource Management, Vol. 34, No. 2, pp. 124-147. https://doi.org/10.1177/2397002220909069

Primecz, H.; Mahadevan, J.; Romani, L. (2016a). "Why is cross-cultural management scholarship blind to power relations? Investigating ethnicity, language, gender, and religion in power-laden contexts", International Journal of Cross-Cultural Management, Vol. 16, No. 2, p. 127-136. DOI: $10.1177 / 1470595816666154$

Primecz, H.; Romani, L.; Sackmann, S.A. (2009). Editorial. "Cross-Cultural Management Research: contributions from various paradigms", International Journal of Cross-Cultural Management, Vol. 9, Iss.3, 267-274.

Primecz, H., Toarniczky, A., Kiss, Cs., Csillag, S., Szilas R., Milassin, A., Bácsi K. (2016b). “ICT’s impact on work family interference. The cases of 'employee friendly organizations", Intersections. East European Journal of Society and Politics, 2, 3, 61-83. DOI: 10.17356/ieejsp.v2i3.158.

Romani, L., Barmeyer, C.; Primecz, H.; Pilhofer, K. (2018). "Cross-cultural management studies: state of the field in four research paradigms", International Studies of Management \& Organization, Vol. 48, Iss. 3, pp. 247-263, DOI: 10.1080/00208825.2018.1480918 
Romani, L.; Sackmann, S. A.; Primecz, H. (2011). "Culture and negotiated meanings: the value of considering meaning systems and power imbalance for cross-cultural management", In H. Primecz; L. Romani; S. Sackmann (eds): Cross-Cultural Management in Practice. Culture and Negotiated Meaning, Edward Elgar, Cheltenham, pp. 1-17.

Salamin, X., \& Hanappi, D. (2014). "Women and international assignments: A systematic literature review exploring textual data by correspondence analysis". Journal of Global Mobility, Vol. 2, Iss. 3, pp. 343-374.

Schwandt, T. (2000). "Three epistemological stances for qualitative enquiry: Interpretivism, hermeneutics, and social constructivism", Norman K. Denzin and Yvonna S. Lincoln (Eds.), The Handbook of Qualitative Research, Second Edition, Thousand Oaks, Sage Publications, 189-213.

Shaffer, M.A., Kraimer, M. L., Chen, Y-P., Chen, M.C. (2012). "Choices, Challenges, and Career Consequences of Global Work Experiences: A Review and Future Agenda", Journal of Management, Vol 38, No. 4, 1282-1327. DOI: 10.1177/0149206312441834

Sullivan, C. and Lewis, S. (2001). 'Home-based Telework, Gender, and the Synchronization of Work and Family: Perspectives of Teleworkers and their Co-residents", Gender, Work and Organization, Vol. 8., No. 2, pp. 123-145. https://doi.org/10.1111/1468-0432.00125

Tahvanainen, M., Welch, D. \& Worm, 2V. (2005): Implications of Short-term International Assignments, European Management Journal, Vol. 23, No. 6, pp. 663-673.

doi:10.1016/j.emj.2005.10.011

Verger, N. B., Urbanowicz, A., Shankland, R., McAloney-Kocaman, K. (2021): Coping in isolation: Predictors of individual and household risks and resilience against the COVID-19 pandemic, Social Sciences \& Humanities Open, 3(1), 100123. https://doi.org/10.1016/j.ssaho.2021.100123

Welch, C.; Piekkari, R.; Plakoyiannaki, E.; Paavilainen-Mäntymäki, E. (2011). "Theorising from case studies: Towards a pluralist future for international business research", Journal of International Business Studies, Vol. 42, Iss. 5, pp. 740-762.

Welch, D. E., Welch, L. S., \& Worm, V. (2007). „The international business traveller: A neglected but strategic human resource.” International Journal of Human Resource Management, 18: 173-183.

Wheatley, D. (2013): Location, Vocation, Location? Spatial Entrapment among Women in Dual Career Households, Gender, Work, and Organization, Vol. 20 No. 6., 720-736. doi:10.1111/gwao.12005. 
Table 1. Main characteristics of the interviewees

\begin{tabular}{|c|c|c|c|c|c|c|}
\hline Name & $\begin{array}{l}\text { Country of } \\
\text { origin }\end{array}$ & $\begin{array}{l}\text { Number } \\
\text { and age of } \\
\text { children }\end{array}$ & $\begin{array}{l}\text { Present } \\
\text { country }\end{array}$ & $\begin{array}{l}\text { Country } \\
\text { lived } \\
\text { before }\end{array}$ & $\begin{array}{l}\text { Length of } \\
\text { Interview } \\
\text { and } \\
\text { language }\end{array}$ & $\begin{array}{l}\text { Partner or } \\
\text { help }\end{array}$ \\
\hline Kinga & Hungary & $\begin{array}{l}\text { two }(10- \\
\text { twins) }\end{array}$ & Hungary & USA & $\begin{array}{l}47 \\
\text { Hungarian }\end{array}$ & $\begin{array}{l}\text { babysitter, } \\
\text { husband }\end{array}$ \\
\hline Ramona & Romania & $\begin{array}{l}\text { two (11, } \\
13)\end{array}$ & Germany & $\begin{array}{l}\text { UK, } \\
\text { Hungary }\end{array}$ & $\begin{array}{l}46 \\
\text { English }\end{array}$ & husband \\
\hline Kirsi & Finland & $\begin{array}{l}\text { two }(12, \\
15)\end{array}$ & Finland & Luxemburg & $\begin{array}{l}30 \\
\text { English }\end{array}$ & husband, \\
\hline Norma & Finland & one (3) & Finland & $\begin{array}{l}\text { New } \\
\text { Zealand, } \\
\text { Spain }\end{array}$ & 27 English & $\begin{array}{l}\text { partner, } \\
\text { grandma }\end{array}$ \\
\hline Stella & Austria & one (9) & Austria & $\begin{array}{l}\text { Norway, } \\
\text { Switzerland }\end{array}$ & 20 English & $\begin{array}{l}\text { second } \\
\text { husband }\end{array}$ \\
\hline Petra & Hungary & two $(4,17)$ & Hungary & $\begin{array}{l}\text { Canada, } \\
\text { Estonia, } \\
\text { France }\end{array}$ & $\begin{array}{l}40 \\
\text { Hungarian }\end{array}$ & $\begin{array}{l}\text { second } \\
\text { husband, } \\
\text { grandma }\end{array}$ \\
\hline Annabelle & France & two $(3,1)$ & Germany & Sweden & 31 English & $\begin{array}{l}\text { husband, } \\
\text { grandma, } \\
\text { babysitter } \\
\text { (just left) }\end{array}$ \\
\hline Katalin & Hungary & one (8) & Hungary & - & $\begin{array}{l}46 \\
\text { Hungarian }\end{array}$ & $\begin{array}{l}\text { husband, } \\
\text { grandma }\end{array}$ \\
\hline Gloria & Spain & one (5) & Spain & Bolivia & 48 English & $\begin{array}{l}\text { husband, } \\
\text { grandma (in } \\
\text { Bolivia) }\end{array}$ \\
\hline Emese & Hungary & two $(6,4)$ & Hungary & - & $\begin{array}{l}29 \\
\text { Hungarian }\end{array}$ & $\begin{array}{l}\text { husband, } \\
\text { grandma }\end{array}$ \\
\hline Imola & Romania & two $(6,8)$ & Hungary & $\begin{array}{l}\text { Switzerland } \\
\text { UK }\end{array}$ & $\begin{array}{l}33 \\
\text { Hungarian }\end{array}$ & husband \\
\hline Charlotte & $\begin{array}{l}\text { UK } \\
\text { (France) }\end{array}$ & two $(12,9)$ & France & $\begin{array}{l}\text { France, } \\
\text { Syria, India }\end{array}$ & 33 English & husband \\
\hline
\end{tabular}

Source: author's compilation 
Table 2 Main themes with codes, underlying issues and future trajectories

\begin{tabular}{|c|c|c|}
\hline Main themes with codes & Underlying issues & Future \\
\hline $\begin{array}{l}\text { international expert women } \\
\text { work-family arrangements } \\
\text { - } \quad \text { international career } \\
\text { - living abroad } \\
\text { - experience } \\
\text { - } \text { maternity leave } \\
\text { - childcare } \\
\text { - length of travel } \\
\text { - international travel } \\
\text { - grandma } \\
\text { - } \text { father/husband/partner } \\
\end{array}$ & \multirow{3}{*}{$\begin{array}{l}\text { efforts to maintain some } \\
\text { sorts of gender equality } \\
\text { while working from home }\end{array}$} & \multirow{3}{*}{ Future uncertainty } \\
\hline $\begin{array}{l}\text { change in work setting - } \\
\text { unnecessary travel } \\
\text { - increasing amount of } \\
\text { work } \\
\text { - international online } \\
\text { work } \\
\text { - } \text { solution in work } \\
\text { - tired of travel } \\
\text { - job loss } \\
\text { - environmentally } \\
\text { unsustainable } \\
\text { international work } \\
\end{array}$ & & \\
\hline $\begin{array}{l}\text { maintaining good balance } \\
\text { between professional work } \\
\text { and family in home office } \\
\text { - work - family conflict } \\
\text { - work - life imbalance } \\
\text { - reconciliation of } \\
\text { schedules with family } \\
\text { - home schooling } \\
\text { - intensive mothering } \\
\text { - limited uses of gadget } \\
\text { - change of use of } \\
\text { gadgets }\end{array}$ & & \\
\hline & & \\
\hline
\end{tabular}

Source: author's compilation 